\title{
Application of Satellite Imagery and Water Indices to the Hydrography of the Cetina RiverBasin (Middle Adriatic)
}

\author{
Tea Duplančić Leder ${ }^{a}$, Nenad Leder ${ }^{b}$, Martina Baučića
}

The paper gives a brief description of the remote sensing method used for the identification and extraction of water surfaces. Landsat 8 and Sentinel 2 satellite imagery was used to separate land from bodies of water in the complex karst area surrounding the Croatian Cetina River, flowing into the Adriatic Sea. Water indexing methods are presented in detail. The most frequently used water indices were selected: NDWI, MNDWI, AWEI_nsh, AWEI_sh, WRI and LSWI, and their results compared. The combination of satellite imagery and calculated water indices is concluded to be very useful for the identification and mapping of the area and banks of lakes, riverine zones, river mouths and the coastline in the coastal zone. Landsat 8 satellite imagery is slightly inferior to Sentinel 2 due to lower image resolution. The best results were obtained with the NDWI water index and the worst with LSWI.

\section{KEY WORDS \\ $\sim$ Water index \\ $\sim$ Sentinel 2 \\ $\sim$ Landsat 8 \\ $\sim$ Riverine zone \\ $\sim$ Coastal zone}

a. University of Split, Faculty of Civil Engineering, Architecture and Geodesy e-mail: tleder@gradst.hr b. University of Split, Faculty of Maritime Studies, Split, Croatia e-mail: nleder@pfst.hr doi: 10.7225/toms.v09.n02.020

This work is licensed under (cc) BY

\section{INTRODUCTION}

Hydrography is the branch of applied sciences which deals with the measurement and description of the physical features of oceans, seas, coastal areas, lakes and rivers, as well as with the prediction of their change over time, for the primary purpose of safety of navigation and in support of all other marine activities, including economic development, security and defense, scientific research, and environmental protection (International Hydrographic Organization, 2020).

Hydrography underpins many other activities associated with bodies of water, including coastal zone management and marine science. One of the most important tasks of hydrography in coastal zone management is to determine the coastline of coastal and riverine zones.

Water is a significant resource and an important factor of the land cover. Its changes have a considerable effect on the climate and environment of a particular area. A variety of factors cause changes in bodies of water, including climate change that has resulted in drought, erosion, floods and various types of water pollution. Remote sensing surface water distribution monitoring has a number of advantages, such as low cost, high frequency of data acquisition, wide coverage and low interference of surface conditions. The method is used in water resource assessment, hydrography, coastal zone management and environmental impact studies.

Since the beginnings of implementation of remote sensing water extraction technique almost forty years ago (Work and Gilmer, 1976), numerous studies have focused on algorithms for extracting water development.

The paper briefly presents remote sensing methods used for water surface identification and extraction. Six commonly 
used water indexing methods or algorithms based on algebraic operations in two or more spectral channels have been compared, applied to the Cetina River basin. Landsat 8 and Sentinel 2 satellite missions have been selected as the sources of data used in this study, which has proven optimal for this purpose in the cost-benefit analysis.

The main goal of this paper is to evaluate the potential of the application of satellite remote sensing and water indices to differentiate land from bodies of water in the karst area of the Cetina River, with special emphasis on the area of Cetina River inflow into the sea.

\section{MATERIALS AND METHODS}

\subsection{Study Area}

The Cetina River belongs to the Adriatic basin. It springs in the northwestern part of the Dinara Mountain at the altitude of $385 \mathrm{~m}$ and is $105 \mathrm{~km}$ long. From its spring, the river flows through the karst area of the Sinj Field, southward through a canyon and finally into the Adriatic Sea in the town of Omiš. The catchment partly lies in the mountains and partially in what is morphologically a karst field (Figure 1). The Cetina River catchment covers the area of approximately 4,145 km2 (Kadić et al., 2019), divided in two parts by the Dinara Mountain. The eastern part of the catchment (two thirds of the catchment or approx. 2,614 km2), referred to as the "indirect" catchment, is mainly situated in Bosnia and Herzegovina, with a continental climate. The western part has the surface of approx. 1,531 km2 (one third of the catchment). It is the "direct" or topographic catchment, almost entirely situated in the Republic of Croatia, with climate under the strong influence of the Adriatic Sea (Mediterranean climate) (Figure 1). The length of the river from the Glavaš spring to the mouth on the Adriatic Sea in Omiš is 104 km. The entire catchment is situated in karst terrain consisting of very thick layers of limestone and dolomites, with intensive karstification and complex hydrogeological conditions. Cetina is a karst river, its waters circulating between fields through underground karst channels. The entire area is a typical karst terrain.

The Cetina River basin can be divided into two morphological parts: the mountainous area and karst fields. The relationships of these relief units define the movement of surface and groundwater within the basin. Surface flows are mainly found in karst fields and composite or complex structure valleys consisting of canyons, valley expansions and culverts, with the communication of water between the fields taking place underground.
The Cetina River flow regimen reaches its maximum during autumn, the second highest level in the spring, and minimum in the summer. There are several hydroelectric power plants on the river: Peruća, Orlovac, Buško blato, Đale, Zakučac and Kraljevac that have a strong effect on the natural hydrological regimen of the river and the overall area. Peruća Lake (coordinates $43^{\circ} 49^{\prime} \mathrm{N}$ $16^{\circ} 36^{\prime} \mathrm{E}$, surface approximately $15 \mathrm{~km}^{2}$, maximum depth $65 \mathrm{~m}$ ) is an artificial lake in karst terrain and the hub of the Cetina River power system (hydroelectric power plants Peruća, Đale and Zakučac). Cetina River flows into the Adriatic Sea near the town of Omiš (4326'36"N; 16²41'35"E) (Figure 2).

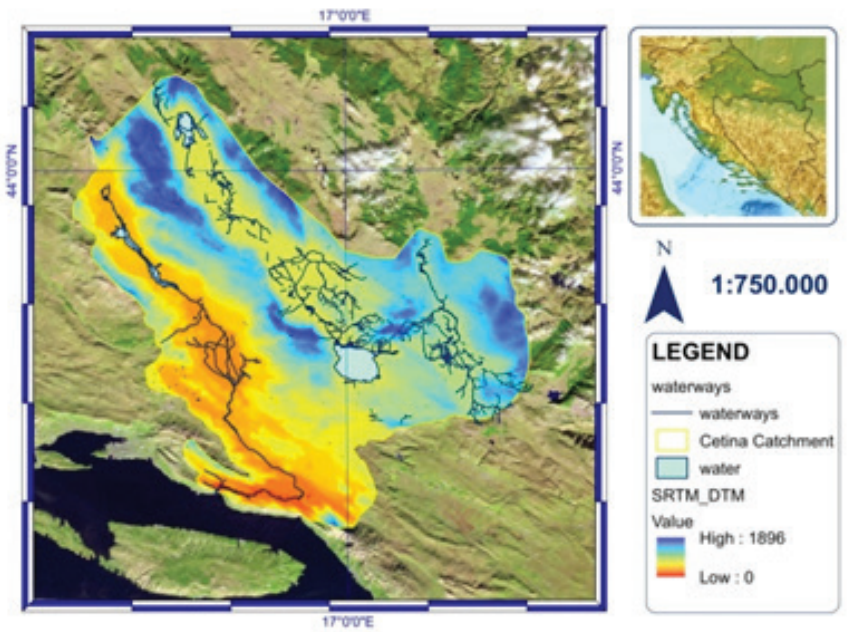

Figure 1.

Cetina River catchment area.

The area examined in this study has the surface of 2,750 $\mathrm{km}^{2}$ and is situated between $43^{\circ} 24^{\prime} 04,84^{\prime \prime} \mathrm{N}$ latitude and $16^{\circ} 23^{\prime} 11,75^{\prime \prime} \mathrm{E}$ longitude up to $43^{\circ} 59^{\prime} 21,35^{\prime \prime} \mathrm{N}$ latitude and $16^{\circ} 54^{\prime} 10,59^{\prime \prime}$ E longitude. It is located within the yellow rectangle in Figure 2 and includes the topographic catchment of the Cetina River (Figure 2). The whole area was tested with six water indices; the results are for better insights presented in two characteristic larger areas: (a) Peruća Lake (purple) and (b) the mouth of the Cetina River (purple) (Figure 2). Both areas examined have still water (lake and sea) and permanent watercourses (river). Likewise, both larger areas are mostly mountains, with some lowlands. The first area for which the results are presented is the northern part of the Peruća Lake shown in Figure 2, top right. The second area is the mouth of the Cetina River shown in Figure 2, bottom right. 

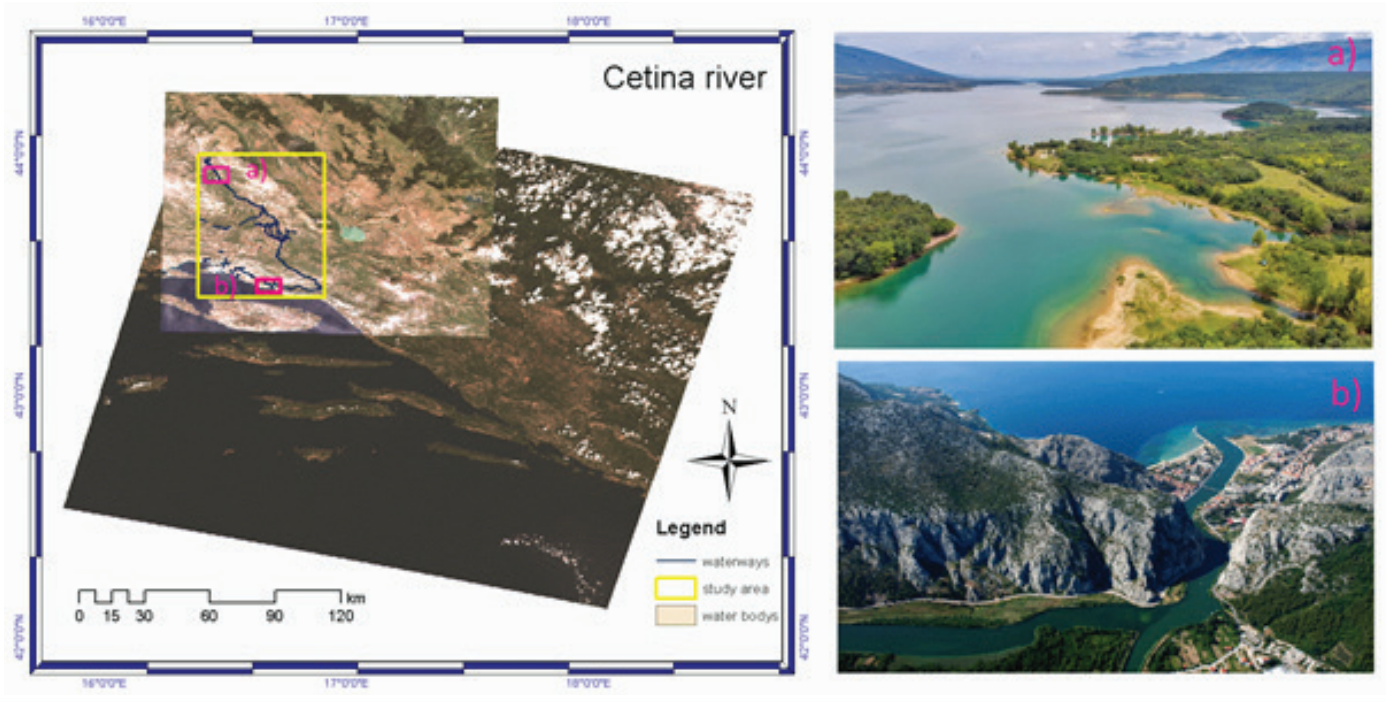

Figure 2.

Area examined (yellow) and two larger areas: (a) Peruća Lake (purple) and (b) the Cetina River mouth (purple) as caught on Landsat 8 and Sentinel 2A satellite images.

\subsection{Materials}

Satellite mission data were used to detect and extract water (sea) surfaces using the water index calculation method.

The cost-benefit analysis for this study indicated two free satellite missions, Landsat 8 and Sentinel 2, as optimal data sources. Satellite images from early September 2018 were used, taken in similar weather conditions around 10 am (Table 1).

Landsat 8 (launched in early 2013) is the latest of NASA's (National Aeronautics and Space Administration) longestrunning multispectral satellite observation mission series. The mission has 9 sensors in the Operational Land Imager (OLI) visible and infrared spectrum range with $15 \mathrm{~m}$ panchromatic spatial resolution, and $30 \mathrm{~m}$ multispectral channel spatial resolution, and 2 Thematic Mapper (TM) and Enhanced Thematic Mapper Plus $(\mathrm{ETM}+)$ sensors in the thermal infrared range with 100 $\mathrm{m}$ spatial resolution (Figure 3 ). The data can be obtained free of charge at USGS (United States Geological Survey) explorer (https://earthexplorer.usgs.gov/).

Free ESA (European Space Agency) satellite Sentinel 2 observation mission (Sentinel-2A and Sentinel-2B, launched
2015 and 2017) is part of the Copernicus satellite program (Sentinel 1-10). The mission is complementary to the previous SPOT mission. It is a multispectral 13 channel mission in the visible, near infrared and shortwave infrared part of the spectrum (Figure 3). Spatial resolution is $10 \mathrm{~m}, 20 \mathrm{~m}$ and $60 \mathrm{~m}$, temporal resolution is 5 days, and the width range is $290 \mathrm{~km}$. Sentinel data can be obtained free of charge from the Copernicus Open Access Hub (https://scihub.copernicus.eu/), while the atmospheric condition scene correction can be conducted using the SEN2COR open application.

September was selected for satellite imagery as electromagnetic radiation from the Sun is still strong at this time of the year and the reflection is strong. Temperatures are high but not excessive, and pressure, humidity and atmospheric correction are not very high. This period is also characterized by the lack of sudden temperature changes and sudden chlorophyll booms that affect water color. As for the coastal areas, since there are not as many swimmers or vessels as in the summer, there is no water turbidity or water color change.

Table 1.

Satellite images used in the study.

\begin{tabular}{lllllll} 
Sensor & Date & Time (UTC) & Temp..$^{\circ} \mathrm{C}$ & Pressure hPa & Humidity \% & Source \\
\hline Landsat 8 & 06-09-2018 & 9h 35min & 27.7 & 1012.3 & 42.18 & USGS explorer \\
\hline Sentinel 2A & $10-09-2018$ & 9h 50min & 28.0 & 1020.2 & 30.56 & Copernicus Open Access Hub \\
\hline
\end{tabular}




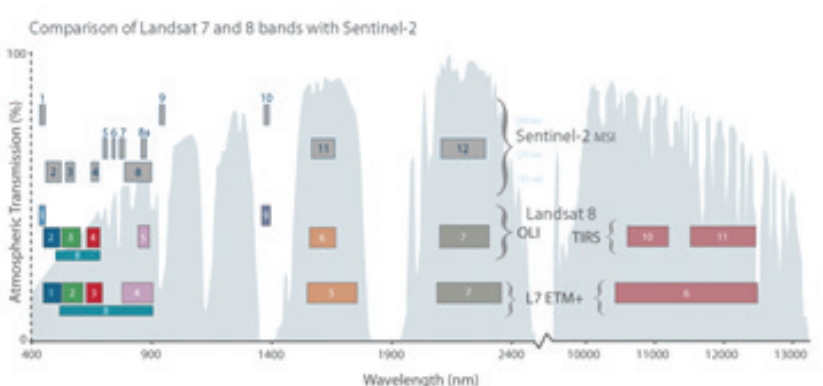

Figure 3.

Comparison of bands, wavelengths and spatial resolution of Landsat 7 and Landsat 8 with the Sentinel 2 satellite mission (according Wulder, et al., 2019).

\subsection{Methodology}

There are many methods for automated identification of bodies of water by satellite remote sensing scene. Such methods are divided into active satellite mission methods, which use the radar portion of electromagnetic radiation (Guerreonero Robinson, et al., 2013) and passive satellite mission methods, the most commonly used methods of which are divided into three categories (Jiang et al., 2014):

1. The spectral channel method identifies water surfaces by finding thresholds in one or more spectral channels. It is simple to apply, but shadows are frequently incorrectly classified due to topography, urban areas or other background irregularities (Rundquist et al., 1987);

2. The classification method applies supervised or unsupervised machine-learning algorithms to the extraction of bodies of water from multispectral scenes (Otukei and Blaschke, 2010);

a. Supervised classification usually uses maximumlikelihood classifiers, decision trees, artificial neural networks or support vector machines method;

b. Unsupervised classification uses K-means or iterative self-organizing data analysis (ISODATA) (Otukei and Blaschke, 2010; Lu and Weng, 2007).

This method achieves good results, but necessitates prior knowledge of the terrain or existing reference data for the selected samples, aggravating the use of this method on poorly known terrain (Frazier and Page, 2000);

3. The water index method combines different algebraic operations over two or more spectral channels to accentuate the discrepancy between bodies of water and land (Jiang et al., 2012; Lu et al., 2011). The principles used by the method are similar to those of the Normalized Difference Vegetation Index (NDVI) (Townshend and Justice, 1986). The following indices are most commonly used to identify bodies of water: a. Normalized Difference Water Index - NDWI (McFeeters, 1996);

b. Modified Normalized Difference Water Index - MNDWI (Xu, 2006; Du et al., 2016);

c. Automated water extraction index - AWEI (Feyisa et al., 2014);

d. Water Ratio Index - WRI (Shen and Li, 2010); and

e. Land surface water index LSWI (Xiao et al., 2002).

In this paper, water index calculation methods have been used and applied to unsupervised classification, enabling the automation of the entire process. Many authors have lately attempted to improve the results and test the quality of different water indices (Feyisa et al., 2014; Baiocchi et al., 2012; Maglione et al., 2014; Elsahabi et al., 2016; Mukherjee and Samuel, 2016; Sarp and Ozcelik, 2016; Kaplan and Avdan, 2017a) on individual satellite sensors. Some authors have compared multiple indices across multiple sensors, e. g. Kwang (2018) compared the accuracy of 4 water indices on 2 sensors, Zou et al., (2017) compared 9 indices across 3 sensors, and El Kafrawy et al., (2017) 3 indices and 2 remote sensing methods on 2 multispectral sensors.

\subsubsection{Normalized Difference Water Index}

The oldest water index, the Normalized Difference Water Index - NDWI, was proposed by McFeeters for mapping and highlighting the characteristics of bodies of water by remote sensing (McFeeters, 1996) using the near infrared (NIR) and green channels to calculate the water index.

Mathematically, the Normalized Difference Water Index according to McFeeters is expressed as:

$N D W I=($ Green $-N I R) /($ Green $+N I R)$

The algorithm reduces non-water features such as vegetation and soil by suppressing the low NIR reflectance of water features, while simultaneously maximizing the reflectance of water at green wavelengths. As threshold value is 0 , positive values correspond to bodies of water and negative values to other bodies. Although the NDWI has the ability to detect turbid waters (McFeeters, 1996), its main disadvantage is the inability to distinguish between built-up areas and bodies of water, making it difficult to extract water (Xu, 2006).

\subsubsection{Modified normalized water index}

$\mathrm{Xu}$ (2006) modified the McFeeters index by replacing the near-infrared (NIR) with the shortwave (SWIR) channel, thereby improving the extraction of water features especially from builtup areas, reducing and eliminating noise present in the NDWI model. 
MNDWI is mathematically expressed as:

$$
M N D W I=(\text { Green }-S W I R) /(\text { Green }+ \text { SWIR })
$$

\subsubsection{Automated Water Extraction Index}

Automated Water Extraction Index - AWEI was proposed by Feyis et al. (2014) to improve the extraction of bodies of water in areas containing shadows or dark parts, while simultaneously offering a stable threshold value for distinguishing water from other surface objects. The algorithm aims to maximize the enhancement of water features by adding different coefficients (Feyis et al., 2014). Two automated water extraction indices were developed, one of which removes shadow pixels, while the other removes non-water pixels, such as dark built-up surfaces in urban areas (Feyis et al., 2014). AWEI indices can be used in different environmental conditions.

Mathematically, AWEI indexes are presented as:

$A W E I_{n s h}=4 \times($ Green $-S W I R 1)-(0.25 \times N I R+2.75 \times S W I R 2)$

$$
\begin{aligned}
A W E I_{\text {sh }}= & \text { Blue }+2.5 \times \text { Green }-1.5 \times(N I R+\text { SWIR1 }) \\
& -0.25 \times \text { SWIR2 }
\end{aligned}
$$

Index using: (1) $\mathrm{AWEI}_{\mathrm{sh}}$ provides the best water surface extraction where dark shadows and other characteristics such as snow, ice or high albedo built-up areas are present; (2) $\mathrm{AWEI}_{\text {nsh }}$ enables optimal separation of bodies of water from other surfaces; (3) $\mathrm{AWEI}_{\mathrm{sh}}$ and $\mathrm{AWEI}_{\mathrm{nsh}}$ are the best at distinguishing water from high albedo surfaces and shady/dark surfaces; (4) in areas without shadows, dark city backgrounds and low albedo areas, the use of $\mathrm{AWE}_{\text {sh }}$ or $\mathrm{AWEI}_{\text {nsh }}$ (Feyis et al., 2014) is recommended.

\subsubsection{Water Ratio Index}

Water Ratio Index - WRI was proposed (Shen and Li, 2010) as the ratio between total spectral reflectance of the Red and Green channels versus total near-infrared (NIR) and shortwave infrared (SWIR) spectral reflectance.

WRI is mathematically expressed as:

$W R I=($ Green + Red $) /(N I R+S W I R)$

\subsubsection{Land surface water index}

Land surface water index - LSWI was proposed (Xiao et al., 2002) as the ratio between the difference between near infrared (NIR) and shortwave infrared (SWIR) channels and the sum of near infrared (NIR) and shortwave infrared (SWIR) channels.

Mathematically, LSWI can be expressed as:

$L S W I=(N I R-S W I R 1) /(N I R+S W I R 1)$

\subsection{Computation Procedure}

The first stage of scene processing was preprocessing, or atmospheric correction, which eliminates potential absorption and dispersion of electromagnetic waves in the atmosphere. Atmospheric correction of Landsat scenes was performed in NASA's Atmospheric Correction Parameter Calculator (https:// atmcorr.gsfc.nasa.gov), with coordinates, altitudes, and meteorological data on temperature, pressure, and humidity used as correction parameters. The Sentinel Application Platform (SNAP; http://step.esa.int/) calculates the atmospheric correction of Sentinel 2 scenes based on pressure parameters and quantity of ozone.

Following preprocessing, the area examined was cut in both scenes to facilitate computation, after which water indices were calculated for the area in question.

Having calculated water indices, unsupervised classifications were made for the area examined, whereby pixel elements were divided into classes based on their natural association in spectral space. Unlike supervised classification, the first step does not require any knowledge of the space being classified, which is suitable for identification of water surfaces in unfamiliar areas.

Unsupervised classification process was performed in two stages: grouping (into classes) followed by class recognition. Classification was performed using ArcGIS and the ISODATA mathematical algorithm classification, whereby the first 5 classes in the area examined were obtained and subsequently reclassified into two basic classes: water and non-water (land). This method of unsupervised classification and reclassification produces better results than simple classification into 2 classes.

After performing the classification, the overall accuracy of output classification for six selected indices of the two scenes was established. Classification accuracy was established using vector data control points obtained from topographic maps and hydrographic survey sheets, by which they were formed from the confusion matrix and the overall accuracy and Kappa coefficient for each test classification were calculated (Ayyanna et al., 2018; FAO, 2016; Mohd Hasmadi et al., 2009; Pontus et al., 2014; Rwanga and Ndambuki, 2017). 


\section{RESULTS}

Values of water indices for the area examined were calculated and are shown more extensively in two sample areas: (1) the northern part of Peruća Lake (Figure 4) and (2) the mouth of the Cetina River. where the river flows into the sea (Fiaure
5). Google Earth satellite images (up) and Google Street with roads and settlement names (down) are shown on the left side of Figures 4 and 5 for the purpose of comparison of water index results with the actual situation on site. The percentages of land and water surface areas obtained by different indices in the areas examined were calculated (Figure 4) and overall accuracy, as well

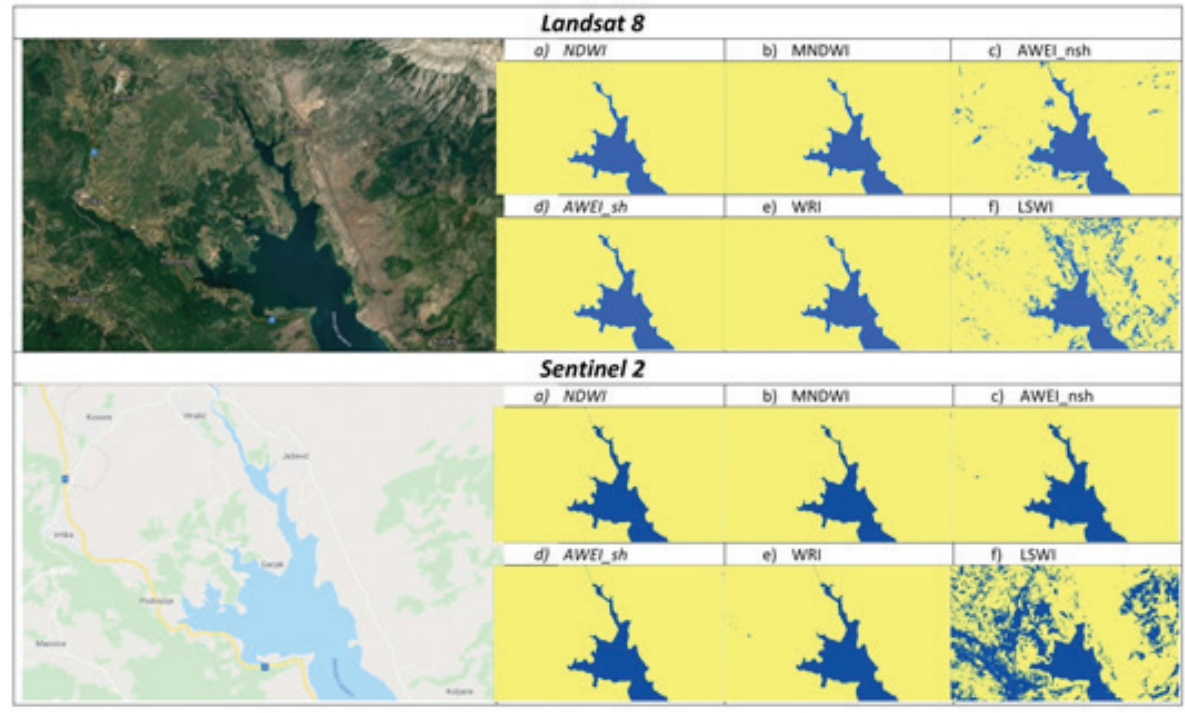

Figure 4.

Values of water indices calculated for the area of Peruća Lake:

a) NDWI; b) MNDWI; c) AWEI_nsh, d) AWEI_sh e) WRI and f) LSWI.

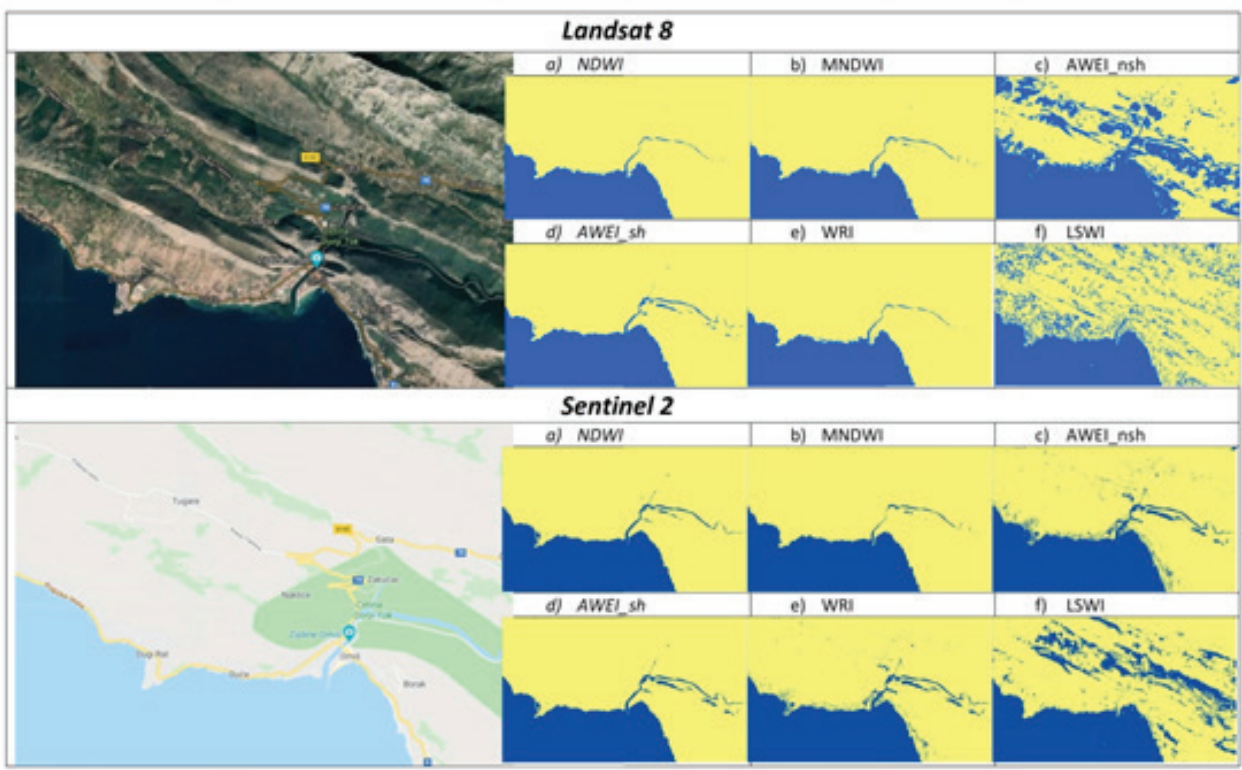

Figure 5.

Values of water indices calculated for the area of the mouth of Cetina River:

a) NDWI; b) MNDWI; c) AWEI_nsh, d) AWEI_sh e) WRI and f) LSWI. 
Table 2.

Overall accuracy of previous research results (\%).

\begin{tabular}{llllllll} 
Authors & Satellite & NDWI & MNDWI & AWEI_sh & AWEI_nsh & WRI & LSWI \\
\hline $\begin{array}{l}\text { Zhou et al., } \\
2017\end{array}$ & L8 & 95.7 & 94.6 & 95.3 & 95.4 & - & 94.1 \\
\cline { 2 - 7 } & S2 & 95.6 & 95.1 & 95.5 & 94.8 & - & 94.4 \\
\hline \multirow{2}{*}{$\begin{array}{l}\text { Kwang et al., } \\
2018\end{array}$} & L8 & 99.8 & 99.6 & 98.8 & 98.6 & - & - \\
\cline { 2 - 7 } & S2 & 99.4 & 99.9 & 99.6 & 98.6 & - & - \\
\hline
\end{tabular}

Table 3.

Kappa coefficients of water indices obtained by ISODAT classifications from previous research.

\begin{tabular}{llllllll} 
Authors & Satellite & NDWI & MNDWI & AWEI_sh & AWEI_nsh & WRI & LSWI \\
\hline $\begin{array}{l}\text { Zhou et al., } \\
2017\end{array}$ & L8 & 0.915 & 0.891 & 0.907 & 0.909 & - & 0.881 \\
\cline { 2 - 7 } $\begin{array}{l}\text { Kwang et al., } \\
2018\end{array}$ & L8 & 0.913 & 0.897 & 0.910 & 0.897 & - & - \\
\cline { 2 - 7 } & S2 & 0.997 & 0.987 & 0.969 & 0.964 & - & - \\
\hline
\end{tabular}

as the Kappa coefficient for the classification of Landsat 8 (Table 3) and Sentinel 2 (Table 4) satellite images obtained. Furthermore, the results thus obtained were compared with those of previous water resource surveys published in scientific papers (Tables 2 and 3).

The values of water indices calculated for the Peruća Lake area are presented in Figure 4. The conclusion is that satellite images can be used to identify lake surfaces and banks, although image quality depends on the type of satellite.

Figure 5 shows the values of water indices calculated for the mouth of Cetina River, indicating that both the river and the bank, as well as its mouth in the vicinity of the town of Omiš, are perfectly discernible from satellite images. Furthermore, it is important to emphasize that the coastline near the mouth of the Cetina River is also identified very well.

The results obtained with the Landsat 8 satellite images are slightly inferior to those from the Sentinel 2 due to lower image resolution preventing the recognition of narrow watercourses and small reservoirs. An example of this situation is visible in the middle of the upper part of Figure 4 and in the middle right of Figure 5.

In spite of low air humidity, the LSWI Index responds to vegetation moisture and built-up areas. The results obtained using Sentinel 2 were inferior to those obtained from Landsat 8 due to the range of NIR and SWIR1 channels. AWEI_nsh also produced poor results in areas under vegetation, built-up areas

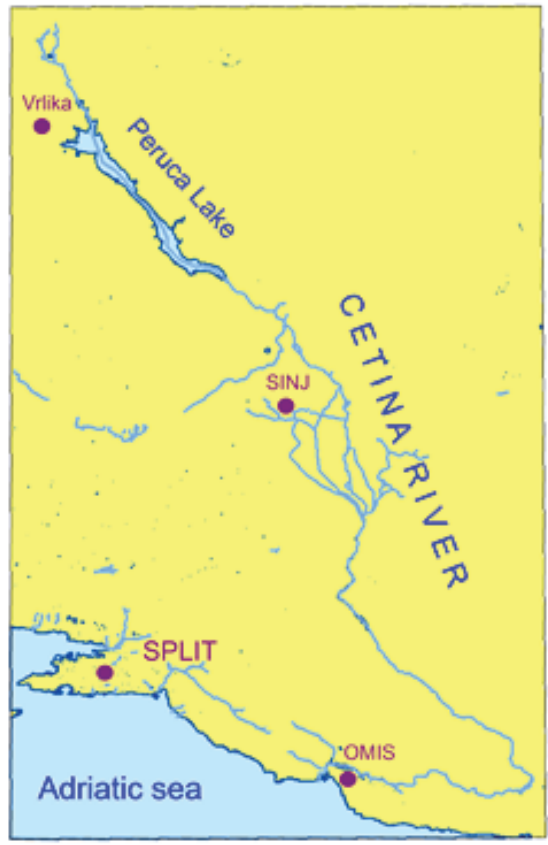

Figure 6.

Vector polygons of the area examined used as reference values for water index comparison. 
and on roads. The WRI index gives satisfactory results but shows noise in the built-up area (settlement Vrlika, middle left in Figure 4 , and in Figure 5 one in a series of settlements along the coastline and the road).

The first step in water index testing was the calculation of the percentage of pixels in each class (Tables 4 and 5), and the percentage of area covered by each class. In the next stage, all bodies of water (rivers, lakes, reservoirs, sea) or water surface polygons in the area examined were vectorized from the topographic maps using the scale 1:25 000 (Figure 6), with polygons used as reference values for evaluation of classification accuracy. Land covers $89.829 \%$ and water $10.171 \%$ of the total area examined. The percentage of classified areas was determined based on 500 and 2500 control points in the area examined. 500 points are concluded to have given satisfactory results for a small number of classes. After that, vector polygon surfaces were compared with the percentage of area belonging to each class. The final assessment of classification accuracy of each individual water index involved the calculation of overall accuracy and of the Kappa classification coefficient (Tables 4 and 5).

The mean accuracy of water index calculation for Landsat 8 images based on 500 control points is 95.48 , while the mean accuracy for Sentinel 2 images is 96.70 . When AWEI_sh and LSWI indices which give inferior results are omitted, mean accuracy value for Landsat 8 is 99.86 and 99.69 for Sentinel 2. The mean of the Kappa coefficient for Landsat 8 is 0.920 and 0.988 for the four indices giving better results, while the mean value of the Kappa coefficient for Sentinel 2 is 0.929 and 0.988 with better indices.

Table 4.

The values of land and water polygon percentages obtained using different indices; overall accuracy and Kappa coefficient of classification for the Landsat 8 image.

\begin{tabular}{llllllll} 
Landsat 8 & & NDWI & MNDWI & AWEI_sh & AWEI_nsh & WRI & LSWI \\
\hline \multirow{2}{*}{ vector } & Land (\%) & 90.201 & 90.171 & 81.219 & 89.946 & 90.225 & 74.998 \\
\hline \multirow{2}{*}{500} & Water (\%) & 9.799 & 9.829 & 18.781 & 10.054 & 9.775 & 25.002 \\
\hline \multirow{2}{*}{2500} & Land (\%) & 90.2 & 90.2 & 81.2 & 90.0 & 90.2 & 75.0 \\
\cline { 2 - 8 } & Water (\%) & 9.8 & 9.8 & 18.8 & 10.0 & 9.8 & 25.0 \\
\hline \multirow{2}{*}{} & Land (\%) & 90.20 & 90.16 & 81.20 & 89.60 & 90.24 & 75.00 \\
\hline & Water (\%) & 9.80 & 9.84 & 18.80 & 10.40 & 9.76 & 25.00 \\
\hline & Accuracy & 99.87 & 99.90 & 90.16 & 99.84 & 99.84 & 83.25 \\
\hline
\end{tabular}

Table 5 .

The values of land and water polygon percentages obtained using different indices; overall accuracy and Kappa coefficient of classification for the Sentinel 2 image.

\begin{tabular}{|c|c|c|c|c|c|c|c|}
\hline Sentinel 2 & & NDWI & MNDWI & AWEI_sh & AWEI_nsh & WRI & LSWI \\
\hline \multirow[t]{2}{*}{ vector } & Land (\%) & 90.053 & 90.292 & 88.950 & 90.044 & 89.266 & 74.484 \\
\hline & Water (\%) & 9.947 & 9.708 & 11.049 & 9.956 & 10.734 & 25.516 \\
\hline \multirow[t]{2}{*}{500} & Land (\%) & 90.0 & 90.2 & 89.0 & 90.0 & 89.2 & 74.4 \\
\hline & Water (\%) & 10.0 & 9.8 & 11.0 & 10.0 & 10.8 & 25.6 \\
\hline \multirow[t]{4}{*}{2500} & Land (\%) & 90.02 & 90.19 & 89.12 & 89.92 & 89.22 & 74.44 \\
\hline & Water (\%) & 9.98 & 9.81 & 10.88 & 10.08 & 10.78 & 25.56 \\
\hline & Accuracy & 99.96 & 99.77 & 98.74 & 99.95 & 99.09 & 82.68 \\
\hline & Карра & 0.989 & 0.989 & 0.863 & 0.988 & 0.988 & 0.758 \\
\hline
\end{tabular}


The mean accuracy of water index calculation for Landsat 8 images based on 500 control points is 95.48 , while the mean accuracy for Sentinel 2 images is 96.70. When AWEI_sh and LSWI indices which give inferior results are omitted, mean accuracy value for Landsat 8 is 99.86 and 99.69 for Sentinel 2. The mean of the Kappa coefficient for Landsat 8 is 0.920 and 0.988 for the four indices giving better results, while the mean value of the Kappa coefficient for Sentinel 2 is 0.929 and 0.988 with better indices.

\section{DISCUSSION}

We have recently witnessed sudden changes in water surfaces in the Croatian coastal area, manifested in the drying or flooding of certain areas. Many authors are trying to identify the optimum water index as an automated method of water area mapping.

Croatian authors have seldom tried to map water surfaces by remote sensing methods (e.g. Duplančić Leder and Leder, 2019), but the quality of the results obtained has never evaluated. For water surface extraction purposes, the water index method chooses the appropriate satellite image created in optimal atmospheric conditions. For the Cetina River basin, optimal satellite images are taken after the bora wind, when the air is free of clouds and moisture, and clear and well-defined transition between land and water is discernible.

At this particular time of the year, the waters of the Cetina River and Peruća Lake are clear, and the sea is transparent and blue, suitable for water index application. Smaller watercourses, especially reservoirs, have turbidity issues, and their brown color reduces both the reflection of electromagnetic energy and the possibility of water index application.

This study used the free data of Sentinel 2 and Landsat 8 satellite missions. Satellite images were taken in September 2018, four days apart (Landsat on September 6, Sentinel on September 10), in almost identical meteorological conditions, allowing the comparison of the results obtained. At $10 \mathrm{am}$ on September 6, temperature was $27.7^{\circ} \mathrm{C}$, air pressure $1012.3 \mathrm{hPa}$, and humidity $42 \%$, whereas on September 10 , temperature was $28.0{ }^{\circ} \mathrm{C}$, air pressure $1020.2 \mathrm{hPa}$, and humidity $30 \%$ (Table 1). The selected satellite images had optimal reflectance and water color for this study. Before calculating the water index of the images, atmospheric correction with meteorological data was performed.

Both images give similar and satisfactory results for all water indices. The classification accuracy of four water indices - NDWI, MNDWI, AWEI_nsh and WRI - was over 99\%, with water index AWEI_sh having the classification accuracy of over $90 \%$ and LSWI a slightly poorer classification accuracy of over $80 \%$. The accuracy of classification results can thus be concluded to be satisfactory, and considered high. Comparing the two satellite missions, slightly better results have been obtained with Sentinel 2 due to its better spatial resolution. If the results of this analysis are compared with the results obtained by other authors, the results can be concluded to be satisfactory, indicating that accuracy and the Kappa coefficient have been calculated at a large number of control points.

For example, using an unknown number of control points, Kwang et al. (2018) obtained the mean water index accuracy of 99.20 and the mean Kappa coefficient of 0.979 for Landsat 8, and the mean accuracy of 99.37 , and the mean Kappa coefficient of 0.984 (Tables 2 and 3) for Sentinel 2. Using 60 control points, Zhou et al. (2017) obtained the mean accuracy of 95.02, and mean Kappa coefficient of 0.901 for Landsat 8, and the mean accuracy of 95.08, and the mean Kappa coefficient of 0.901 for Sentinel 2 (Tables 2 and 3). Yang et al. (2017) examined Sentinel 2 images and NDWI and MNDWI indices in urban and coastal areas. The mean water index accuracy in urban areas was 97.92, and 98.88 in the coastal area. The Kappa coefficient was 0.645 in urban areas, and 0.839 in the coastal area. These results are similar to those obtained for the examined Cetina River area.

Problems in connection with water index based methods occur in the extraction of small bodies of water, particularly from Landsat images, due to their low spatial resolution. Better results can be obtained from higher resolution commercial satellite missions (WW2, RapidEye...), aerophotogrametric or LIDAR images (Zhou et al., 2017). The limitations of commercial missions are the existence of only near infrared (NIR) channels with visible channels. Most indices give poorer results in built-up areas and especially in cities characterized by a lot of noise, attempted to be avoided by combining the water index method with other methods or by combining different parameters (Figure 4; mountainous part of Peruća Lake with Vrlika settlement on the left; Figure 5 shows the mouth of the Cetina River with the town of Omiš on the right side of the image). A particularly serious problem was encountered in the mountainous areas where low sun elevation creates long shadows and numerous side effects, which combined with low temperature, ice and poorer reflection have proven problematic for some of the indices (Figures $5 \mathrm{c}$ and $5 \mathrm{f}$ ). The conditions for the extraction of water surfaces are considered to be favorable when the angle of elevation of the Sun is above 40 degrees (Kaplan and Avdan, 2017b). The angle of the Sun in the Landsat 8 image was 49.63 degrees and 40.45 degrees in the Sentinel 2 image.

The results of this study are slightly better in case of extraction of coastal than fresh water (Figure 5). Reflection over sea can be concluded to be better due to the different composition of salt water and lower quantity of dissolved substances (higher transparency). Very similar results were obtained by other authors in their studies (e.g. Yang et al., 2017).

The MNDWI index is suitable for the identification of flooded areas in cities, while AWEI indices are intended for areas 
in full shadow and areas covered with ice. The LSWI index is suitable for the identification of moisture content and as such is not well suited for the purposes of this study (Zhou et al., 2017).

\section{CONCLUSION}

In recent years, the International Hydrographic Organization (IHO) has changed the basic purpose of its activity. Namely, its primary goal is no longer limited to the safety of navigation, but has come to include a number of other activities relating to the physical features of oceans, seas, coastal areas, rivers and lakes. One of the most important tasks of hydrography, applied to coastal zone management, is to identify the coastline, coastal and riverine zones.

Since standard hydrographic survey methods are prohibitively expensive and time consuming, this paper used the satellite remote sensing technique and the water index calculation method to distinguish land from bodies of water in the complex karst area of the Croatian Cetina River, flowing into the sea in the vicinity of the town of Omiš. In this area, spatial and temporal changes of water and land are frequent, and there is a need for fast and efficient mapping of these changes.

Landsat 8 (NASA) and Sentinel 2 (ESA) satellite missions were used to obtain satellite images, while NDWI, MNDWI, AWEI, WRI and LSWI indices were used to extract water (sea) and land surfaces.

From the hydrographic point of view, the studied Cetina River area can be divided into three units: Peruća Lake, Cetina River and the mouth of the river on the Adriatic Sea (coastal area). The combination of satellite imagery and calculated water indices can be concluded to be well suited to the identification and mapping (smaller scale maps) of the area and banks of lakes, riverine zones, the river mouth area and the coast in the coastal zone. Furthermore, satellite image quality depends on satellite type.

The results obtained using Landsat 8 satellite images are slightly inferior to those obtained using Sentinel 2 due to lower image resolution. This study has shown the NDWI index as the most appropriate for the identification of bodies of water. The poorest results were obtained with the AWEI_sh and LSWI indices, providing that the LSWI index is primarily used for moisture extraction, rather than for water surfaces, while AWEI_ sh is intended for mapping bodies of water in shaded areas (high mountains), built-up areas and roads. Likewise, it is evident that classification results are slightly better for marine than freshwater areas extraction. The poorest results were obtained in urban areas, especially when the AWEI_sh and LSWI indices, which give inferior results, were used.

\section{ACKNOWLEDGMENTS}

The presented research is partially supported by the KK.01.1.1.02.0027 project co-financed by the State Budget of the Republic of Croatia and by the European Union from the European Fund for Regional Development within the Operational Program "Competitiveness and Cohesion".

\section{REFERENCES}

Ayy anna, A. et al., 2018. Accuracy Assessment of Supervised and Unsupervised Classification using Landsat-8 Imagery of D-7 Shahapur Branch Canal of UKP Command Area Karnataka. International Journal of Current Microbiology and Applied Sciences, 7(07), pp.205-216. Available at:

http://dx.doi.org/10.20546/ijcmas.2018.707.025

Baiocchi, V., Brigante, R., Domenici, D., Radicioni, F., 2012. Coastline Detection Using High Resolution Multispectral Satellite Images, FIG Working Week 2012 - Rome, Italy, $1-15$.

Du, Y. et al., 2016. Water Bodies' Mapping from Sentinel-2 Imagery with Modified Normalized Difference Water Index at 10-m Spatial Resolution Produced by Sharpening the SWIR Band. Remote Sensing, 8(4), p.354. Available at: http://dx.doi.org/10.3390/rs8040354.

Duplančić Leder, T., Leder, N., 2019. A comparison of algorithms for coastline mapping using satellite methods (in Croatian), Hrvatske vode, 110(27), pp.295-304.

El Kafrawy, S. et al., 2017. Performance Evaluation of Shoreline Extraction Methods Based on Remote Sensing Data. Journal of Geography, Environment and Earth Science International, 11(4), pp.1-18. Available at: http://dx.doi.org/10.9734/jgeesi/2017/36233.

Elsahabi, M., Negm, A. \& Hamid M.H. El Tahan, A., 2016. Performances Evaluation of Surface Water Areas Extraction Techniques Using Landsat ETM+ Data: Case Study Aswan High Dam Lake (AHDL). Procedia Technology, 22, pp.1205-1212. Available at: http://dx.doi.org/10.1016/j.protcy.2016.02.001.

Feyisa, G.L. et al., 2014. Automated Water Extraction Index: A new technique for surface water mapping using Landsat imagery. Remote Sensing of Environment, 140, pp.23-35. Available at:

http://dx.doi.org/10.1016/j.rse.2013.08.029.

FAO, 2016. Map Accuracy Assessment and Area Estimation: A Practical Guide, Food and Agriculture Organization (FAO) of the United Nations, Rome.

Frazier, P.S., \& Page, K.J., 2000. Body of water detection and delineation with Landsat TM data, Photogramm. Eng. Remote Sens., 66, pp.1461-1468.

Guerreonero Robinson, D.A., Bijker \& Tolpekin, V.A., 2013. Shoreline detection using TerraSAR-X Quad polarization mode, International Hydrographic Review, November, pp. 15-25.

International Hydrographic Organization, 2020. Definition-of-hydrography, Available at: https://iho.int/en/importance-of-hydrography, accessed on: 20 July 2020.

Jiang, H. et al., 2014. An Automated Method for Extracting Rivers and Lakes from Landsat Imagery. Remote Sensing, 6(6), pp.5067-5089. Available at: http://dx.doi.org/10.3390/rs6065067. 
Jiang, Z. et al., 2011. Water body delineation using index composition and HIS transformation. International Journal of Remote Sensing, 33(11), pp.3402-3421. Available at:

http://dx.doi.org/10.1080/01431161.2011.614967.

Kadić, A. et al., 2019. Hydrological functioning of three karst springs located in the Cetina River catchment in Croatia, Geophysical Research Abstracts, EGU General Assembly, 2019.

Kaplan, G. \& Avdan, U., 2017a. Object-based water body extraction model using Sentinel-2 satellite imagery. European Journal of Remote Sensing, 50(1), pp.137143. Available at:

http://dx.doi.org/10.1080/22797254.2017.1297540.

Kaplan, G. \& Avdan, U., 2017b. Water extraction technique in mountainous areas from satellite images. Journal of Applied Remote Sensing, 11(04), p.1. Available at: http://dx.doi.org/10.1117/1.jrs.11.046002.

Kwang, C., Jnr, E.M.O. \& Amoah, A.S., 2017. Comparing of Landsat 8 and Sentinel 2A using Water Extraction Indexes over Volta River. Journal of Geography and Geology, 10(1), p.1. Available at:

http://dx.doi.org/10.5539/jgg.v10n1p1.

Lu, D. \& Weng, Q., 2007. A survey of image classification methods and techniques for improving classification performance. International Journal of Remote Sensing, 28(5), pp.823-870. Available at: http://dx.doi.org/10.1080/01431160600746456.

Lu, S. et al., 2011. Water body mapping method with $\mathrm{HJ}-1 \mathrm{~A} / \mathrm{B}$ satellite imagery. International Journal of Applied Earth Observation and Geoinformation, 13(3), pp.428-434. Available at:

http://dx.doi.org/10.1016/j.jag.2010.09.006.

Maglione, P., Parente, C. \& Vallario, A., 2014. Coastline extraction using high resolution WorldView-2 satellite imagery. European Journal of Remote Sensing, 47(1), pp.685-699. Available at:

http://dx.doi.org/10.5721/eujrs20144739.

McFeeters, S.K., 1996. The use of the Normalized Difference Water Index (NDWI) in the delineation of open water features. International Journal of Remote Sensing, 17(7), pp.1425-1432. Available at:

http://dx.doi.org/10.1080/01431169608948714.

Mohd Hasmadi, I., Pakhriazad, H.Z., Shahrin, M.F., 2009. Evaluating supervised and unsupervised techniques for land cover mapping using remote sensing data, Malaysian Journal of Society and Space, 5(1), pp.1-10.

Mukherjee, N. \& Samuel, C., 2016. Assessment of the Temporal Variations of Surface Water Bodies in and around Chennai using Landsat Imagery. Indian Journal of Science and Technology, 9(18). Available at: http://dx.doi.org/10.17485/ijst/2016/v9i18/92089.

Otukei, J.R. \& Blaschke, T., 2010. Land cover change assessment using decision trees, support vector machines and maximum likelihood classification algorithms. International Journal of Applied Earth Observation and Geoinformation, 12, pp.S27-S31. Available at: http://dx.doi.org/10.1016/j.jag.2009.11.002.
Olofsson, P. et al., 2014. Good practices for estimating area and assessing accuracy of land change. Remote Sensing of Environment, 148, pp.42-57. Available at: http://dx.doi.org/10.1016/j.rse.2014.02.015.

Rundquist, D.C. et al., 1987. The relationship between summer-season rainfall events and lake-surface area, JAWRA Journal of the American Water Resources Association, 23(3), pp.493-508. Available at:

http://dx.doi.org/10.1111/j.1752-1688.1987.tb00828.x.

Rwanga, S.S. \& Ndambuki, J.M., 2017. Accuracy Assessment of Land Use/Land Cover Classification Using Remote Sensing and GIS. International Journal of Geosciences, 08(04), pp.611-622. Available at:

http://dx.doi.org/10.4236/ijg.2017.84033.

Sarp, G. \& Ozcelik, M., 2017. Water body extraction and change detection using time series: A case study of Lake Burdur, Turkey. Journal of Taibah University for Science, 11(3), pp.381-391. Available at: http://dx.doi.org/10.1016/j.jtusci.2016.04.005.

Shen, L. \& Li, C., 2010. Water body extraction from Landsat ETM+; imagery using adaboost algorithm. 2010 18th International Conference on Geoinformatics. Available at:

http://dx.doi.org/10.1109/geoinformatics.2010.5567762.

Townshend, J.R., Justice, C., 1986. Analysis of the dynamics of African vegetation using the normalized difference vegetation index. International Journal of Remote Sensing, 7(11), pp.1435-1445. Available at: http://dx.doi.org/10.1080/01431168608948946.

Work, E. A. Jr, Gilmer, D. S., 1976. Utilization of Satellite Data for Inventorying Prairie Ponds and Lakes, Photogrammetric Engineering and Remote Sensing, 42(5), pp. 685-694.

Wulder, M.A. et al., 2019. Current status of Landsat program, science, and applications. Remote Sensing of Environment, 225, pp.127-147. Available at: http://dx.doi.org/10.1016/j.rse.2019.02.015.

Xiao, X. et al., 2002. Landscape-scale characterization of cropland in China using Vegetation and Landsat TM images. International Journal of Remote Sensing, 23(18), pp.3579-3594. Available at: http://dx.doi.org/10.1080/01431160110106069.

$\mathrm{Xu}, \mathrm{H} ., 2006$. Modification of normalised difference water index (NDWI) to enhance open water features in remotely sensed imagery. International Journal of Remote Sensing, 27(14), pp.3025-3033. Available at:

http://dx.doi.org/10.1080/01431160600589179.

Yang, X. et al., 2017. Mapping of Urban Surface Water Bodies from Sentinel-2 MSI Imagery at $10 \mathrm{~m}$ Resolution via NDWI-Based Image Sharpening. Remote Sensing, 9(6), p.596. Available at: http://dx.doi.org/10.3390/rs9060596.

Zhou, Y. et al., 2017. Open Surface Water Mapping Algorithms: A Comparison of Water-Related Spectral Indices and Sensors. Water, 9(4), p.256. Available at: http://dx.doi.org/10.3390/w9040256. 